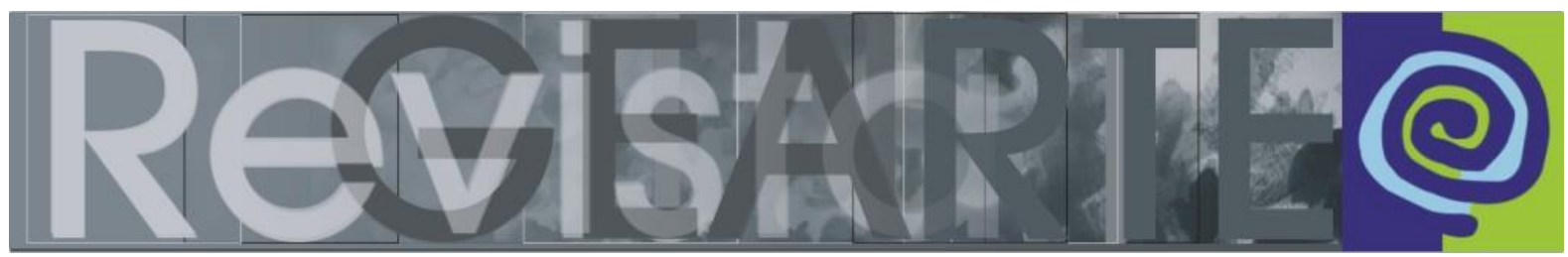

e-ISSN 2357-9854

\title{
O patrimônio artístico e cultural do estado do Espírito Santo, a reformulação do ensino da arte a partir da Base Nacional Comum Curricular e o uso da tecnologia na prática educativa
}

\author{
Claudia Botelho \\ (Secretaria Estadual de Educação do Espírito Santo — SEDU, Vitória/ES, Brasil)
}

\begin{abstract}
RESUMO - O patrimônio artístico e cultural do estado do Espírito Santo, a reformulação do ensino da arte a partir da Base Nacional Comum Curricular e o uso da tecnologia na prática educativa - O presente artigo apresenta a reelaboração do currículo do estado do Espírito SantoEducação Infantil e Ensino Fundamental, no componente curricular Arte, sua interação com a educação multicultural e com o uso da tecnologia no ensino. A revisão do currículo de Arte pela abrangência da Base Nacional Comum Curricular desperta para uma educação que dialogue com as diversidades locais em interação com diferentes culturas nacionais e internacionais. Nesse processo a tecnologia se torna uma ferramenta e uma linguagem de aproximação da cultura diversa entre estudantes de diferentes partes do estado, além de proporcionar a apreciação estética e a interação virtual com obras de artes e de manifestações da cultura popular do estado do Espírito Santo.
\end{abstract}

PALAVRAS-CHAVE

Currículo de Arte. Multiculturalismo. Patrimônio artístico e cultural do Espírito Santo. Tecnologia no ensino da arte.

ABSTRACT - The artistic and cultural heritage of the state of Espírito Santo, the reformulation of art education from the Common National Base Curriculum and the use of technology in educational practice - This article presents the re-elaboration of the curriculum of the State of Espírito Santo - Early Childhood Education and Elementary Education, in the curricular component Arte, its interaction with multicultural education and with the use of technology in education. The revision of the Art curriculum by the scope of the National Common Curricular Base awakens to an education that will dialogue with the local diversities in interaction with different national and international cultures. In this process technology becomes a tool and a language of approach to culture with students from different parts of the state, as well as providing aesthetic appreciation and virtual interaction with works of art and manifestations of popular culture in the state of Espírito Santo.

KEYWORDS

Art Curriculum. Multiculturalism. Artistic and cultural heritage. Technology in art education.

\section{Introdução}

A Base Nacional Comum Curricular- Educação Infantil e Ensino FundamentalBNCC, em consonância com o ensino contemporâneo da arte traz como desafio a inserção da diversidade cultural dos educandos na produção de conhecimento em arte na escola. Os novos documentos de orientações programáticas intentam que não seja estudada nas escolas, apenas a produção artística consagrada pela história da

BOTELHO, Claudia. O patrimônio artístico e cultural do estado do Espírito Santo, a reformulação do 80 ensino da arte a partir da Base Nacional Comum Curricular e o uso da tecnologia na prática educativa. Revista GEARTE, Porto Alegre, v. 6, n. 1, p. 80-91, jan./abr. 2019.

http://dx.doi.org/10.22456/2357-9854.90572 


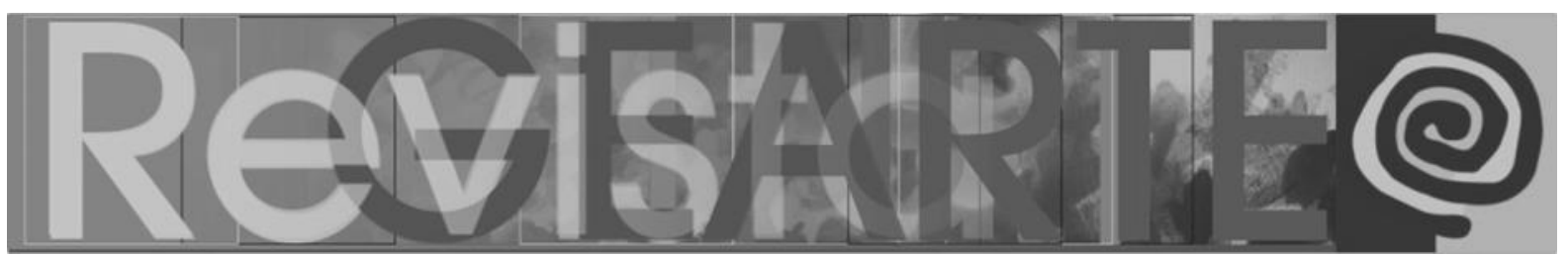

arte europeia e hegemônica, mas que os estudantes reconheçam em suas aproximações locais produções legítimas da arte e da cultura.

Na experiência de reelaboração do currículo do território ${ }^{1}$ do estado do Espírito Santo a diversidade cultural torna-se um dos eixos norteadores do desenho do novo currículo do componente curricular Arte. Porém essa proposta recebeu críticas diversas, que vinham desde especialistas do Conselho Estadual de Educação, que julgou como retrocesso e inferior o documento por não ter as grandes vertentes da arte brasileira, o Modernismo, como foco dos estudos.

Passando por críticas de valores religiosos que questionam a relevância dos estudos de matrizes estéticas africanas e chegando na incompreensão de alguns professores e gestores escolares, que participaram das consultas públicas, em relação a produção artística e cultural local, afirmando esses profissionais que em suas localidades não havia esse tipo de produção.

Essas situações nos levaram a refletir sobre em como superar essas dificuldades para que a vinculação do novo currículo possa se dar de forma efetiva em todos os municípios do estado.

O currículo que foi lançado em 2008 na rede estadual de educação do Espírito Santo, e que ainda se encontra em vigência, já trazia a produção artística e o patrimônio cultural local como objetos de estudos. No entanto, identificamos em pesquisa com os professores da rede estadual, algumas dificuldades de compreender a produção artística e cultural local como produto legitimado para o ensino da arte.

A dificuldade de compreender a produção local como legítima se agrava com outro problema já identificado no Espírito Santo, à falta de pesquisa sobre a produção

1 A coordenação estadual do Programa de Apoio à Implementação da Base Nacional Comum Curricular- Espírito Santo (ProBNCC) adota o nome "Currículo do território do Espírito Santo", uma vez que a reelaboração dos currículos a partir da Base Nacional Comum Curricular foi realizada em parceria entre estado e munícipios. O novo currículo foi elaborado em regime de colaboração entre a rede estadual e as redes municipais de educação. Assim, o novo documento terá abrangência em quase todo território capixaba. 


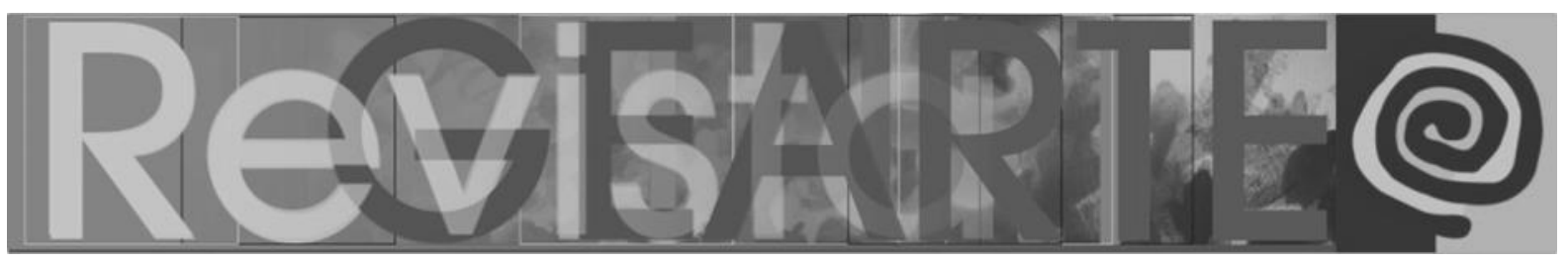

artística do estado. A historiadora e crítica de arte Almerinda da Silva Lopes, expoente nas pesquisas de história da arte do Espírito Santo, queixa-se da quase ausência das pesquisas sobre os artistas capixabas, uma vez que esses, na maioria dos casos, se encontram fora do eixo hegemônico da arte brasileira "Rio x São Paulo". O que dizer então, dos artistas e artesãos do interior do estado, que na maioria das vezes não são nem reconhecidos como produtores arte ou cultura?

Dessa realidade, pensamos em criar um museu virtual do patrimônio artístico e cultural do estado do Espírito Santo. Mapeando obras, produções culturais e manifestações estéticas de diferentes naturezas, por meio de levantamentos bibliográficos, documentais e pesquisas com os próprios professores de arte. $\mathrm{O}$ museu abrigaria as fotografias e informações diversas das obras catalogadas. Entre essas informações estariam: a autoria (quando possível), a localização, a data (também quando possível), as características (técnicas, tamanho e etc.) e o contexto das obras e manifestações culturais catalogadas, podendo ainda ser acrescidas informações sobre os estilos e influências de diferentes correntes estilísticas com essas obras.

O museu reuniria qualquer produção plástica, visuais, musical, cênica, cinematográfica e multimídia, incluindo as manifestações da cultura popular produzidas em diferentes localidades do estado.

A tecnologia torna-se uma grande aliada nesse projeto uma vez que por meio dela poderemos orientar as pesquisas em campo, dos diversos professores do interior do estado; registrar e catalogar as obras levantadas; armazenar o resultado das pesquisas e, principalmente, tornar visível e legitimar as diversas obras e produções artísticas e culturais do estado do Espírito Santo. Além da pesquisa histórica e cultural, a tecnologia digital abre para a possibilidade de produção estética das imagens digitais, a interação com a plataforma e a experimentação com espaços virtuais. 


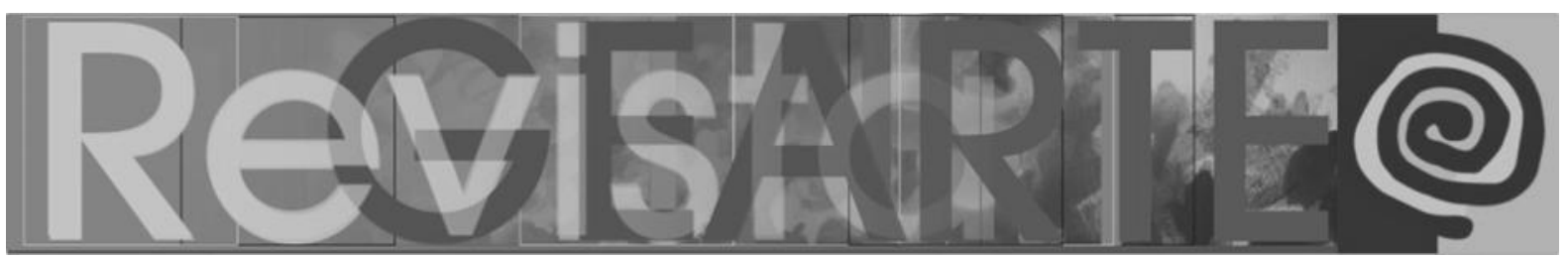

\title{
O Multiculturalismo e os documentos orientadores do Componente Curricular Arte (BNCC, PCN e Currículo do Espírito Santo)
}

A escola é lugar das diferenças, que inúmeras identidades ocupam esse lugar de construção do conhecimento e sabemos também que o conhecimento só acontecerá com efetividade se soubermos olhar as individualidades que compõem cada sujeito. No entanto, na história da educação vimos uma tendência de unificação das culturas e de padronização de comportamento que inviabilizavam as diferentes identidades. Na atualidade, o ensino contemporâneo, sobretudo o ensino da arte, busca corrigir esse erro de desigualdade, onde certas culturas eram privilegiadas sobre as outras. O reconhecimento das diversidades é essenciais na promoção das igualdades de religião, de idade, de gênero, de classe social etc.

Estudiosos da área nos apontam que a preocupação com a relação educação e cultura se encontram cada vez mais presente:

\begin{abstract}
Hoje esta consciência do caráter homogeneizador e monocultural da escola é cada vez mais forte, assim como a consciência da necessidade de romper com esta e construir práticas educativas em que a questão da diferença e do multiculturalismo se façam cada vez mais presentes. Uma outra contribuição que consideramos muito interessante para uma nova compreensão das relações entre educação e cultura(s) diz respeito a uma concepção da escola como um espaço de cruzamento de culturas, fluido e complexo, atravessado por tensões e conflitos. (MOREIRA; CANDAU, 2008, p. 15).
\end{abstract}

A importância do ensino multicultural é demarcada por estudos que vêm se acentuando nas últimas décadas. O cruzamento de estudos sociológicos com os do campo da educação vem provando a necessária existência de uma educação multicultural.

No ensino da arte, sobretudo, essa visão de educação requer ainda mais atenção. Como parte da cultura, a arte também se faz pela diversidade, situando-se no contexto brasileiro, a arte a ser ensinada nas escolas carrega traços étnicos, religiosos e de gêneros mais diversos. Como afirma Barbosa, "[...] a educação é mediatizada pelo mundo em que se vive, formada pela cultura, influenciada por 


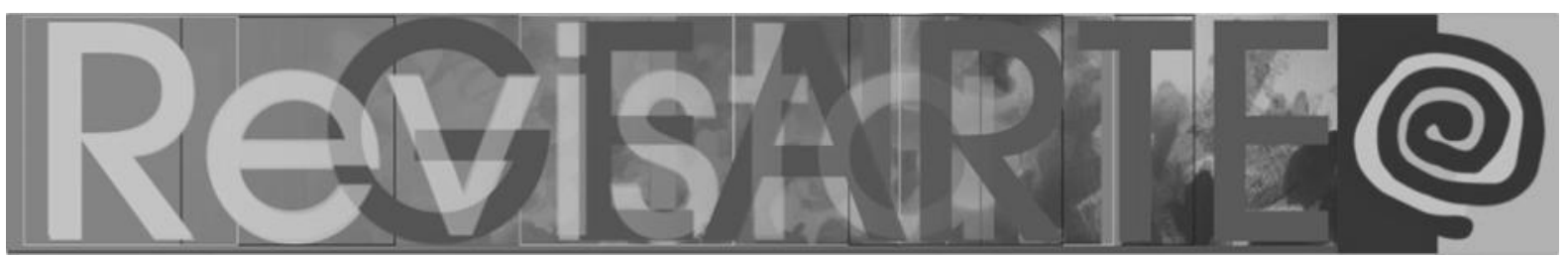

linguagens, impactada por crenças, clarificada pela necessidade, afetada por valores e moderada pela individualidade [...]" (BARBOSA, 2006, p.12).

$\mathrm{Na}$ construção de documentos orientadores da prática docente é importante que essas especificidades sejam evidenciadas e respeitadas. Os documentos curriculares são atitudes políticas que impactam diretamente na vida de milhares de crianças e adolescentes. Dessa forma, a defesa de um ensino que respeite a diversidade cultural é de suma importância:

[...] Multiculturalismo em educação envolve, ainda, um posicionamento claro a favor da luta contra a opressão e a discriminação a que certos grupos minoritários têm, historicamente, sido submetidos por grupos mais poderosos e privilegiados. (MOREIRA, CANDAU, 2008, p7).

A disputa desse espaço de reconhecimento das minorias instalou na educação já algum tempo. Os Parâmetros Curriculares Nacionais- Arte, de 1997, apresentam a preocupação com a diversidade cultural na formação do povo brasileiro, com os seguintes objetivos:

Conhecer características fundamentais do Brasil nas dimensões sociais, materiais e culturais como meio para construir progressivamente a noção de identidade nacional e pessoal e o sentimento de pertinência ao País;

Conhecer e valorizar a pluralidade do patrimônio sociocultural brasileiro, bem como aspectos socioculturais de outros povos e nações, posicionando-se contra qualquer discriminação baseada em diferenças culturais, de classe social, de crenças, de sexo, de etnia ou outras características individuais e sociais." (PCNs- ARTE,1997, p. 7).

No texto dos Parâmetros Curriculares Nacionais (PCNs) ao apresentar a expressão "características fundamentais do Brasil" e algumas dimensões (sociais, materiais e culturais) aponta para a diversidade, nos aspectos social, material e cultural, que colaboram com a construção da noção de identidade nacional e pessoal. $\mathrm{Na}$ continuidade do texto aparecem as expressões "pluralidade socioculturais" e "contra qualquer discriminação baseada em diferenças culturais, de classe social, de crenças, de sexo, de etnia ou outras características individuais e sociais", o que deixa evidente qual direcionamento o ensino precisa tomar para se construir uma educação que respeite as diferenças. 


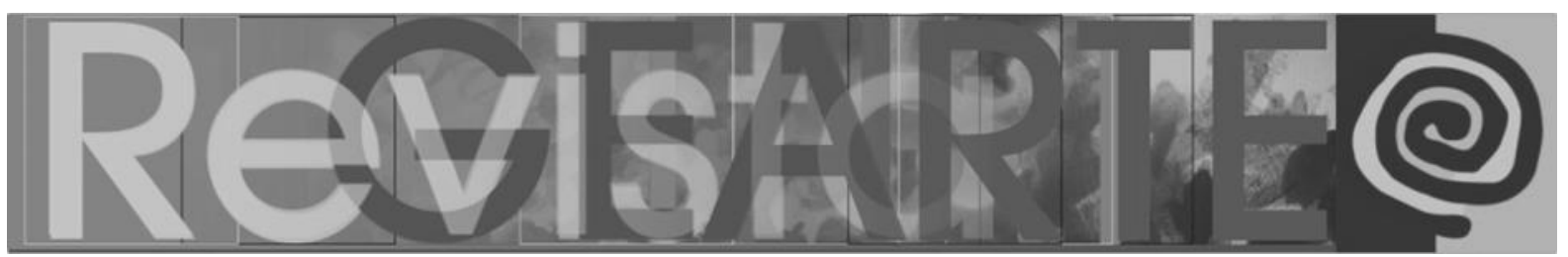

Depois do aparecimento dos PCNs os currículos de várias redes estaduais e municipais caminharam para a construção que reconheçam as pluralidades culturais, no entanto, esse movimento ainda se manteve distante das salas de aulas. Na Base Nacional Comum Curricular (BNCC), no componente curricular Arte, a questão do multiculturalismo volta aparece como orientação oficial.

\begin{abstract}
O componente curricular Arte contribui para a [...] a interação crítica dos alunos com a complexidade do mundo, além de favorecer o respeito às diferenças e o diálogo intercultural, pluriétnico e plurilíngue, importantes para o exercício da cidadania. A Arte propicia a troca entre culturas e favorece o reconhecimento de semelhanças e diferenças entre elas. Nesse sentido, as manifestações artísticas não podem ser reduzidas às produções legitimadas pelas instituições culturais e veiculadas pela mídia, tampouco a prática artística pode ser vista como mera aquisição de códigos e técnicas. (BNCC, 2017, p. 191).
\end{abstract}

O texto introdutório do componente curricular Arte, na BNCC continua defendendo o respeito às diferenças e a interação intercultural, valorizando ainda que as produções não hegemônicas da arte também sejam respeitadas. O texto não deixa dúvida do viés multicultural que o ensino da arte precisa ser atendido no desenho dos currículos reelaborados a partir da Base Nacional Comum Curricular. No entanto, essa perspectiva na educação, em especial na Arte/Educação, ainda precisa ser difundida entre as práticas em salas de aulas.

Na reelaboração do currículo do território do Espírito Santo, para o componente curricular Arte, a questão do multiculturalismo se tornou um princípio teórico e políticopedagógico que perpassa por todo documento. A intenção do respeito, às diferenças entre: etnias, religiões, gênero, classes sociais e econômicas e as deficiências corporais e mentais, é colocada na redação do texto introdutório e das habilidades das diferentes linguagens, séries e etapas de ensino em arte.

O texto introdutório trata-se de um texto convite que chama o professor a colocar a arte em circulação, levando para dentro da escola o que é produzido em seu entorno, articulando um pensamento crítico e reflexivo do impacto dessa produção na construção das diferentes identidades que ocupam as salas de aulas. 


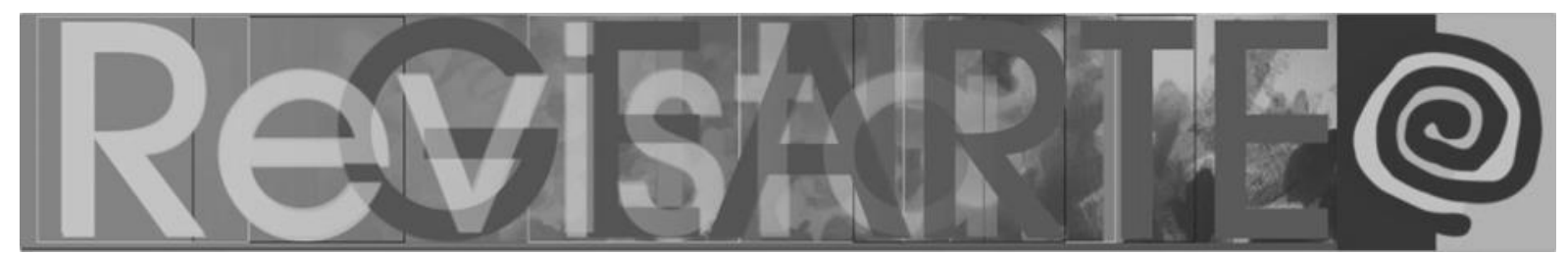

“Eu quero é botar meu bloco na rua..." e o Referencial Curricular de Arte do Estado do Espírito Santo quer é colocar a Arte em todos os lugares, na rua, na escola, na comunidade, na cidade e no campo, na tribo e no terreiro, na casa ou em qualquer moradia. Com este documento objetiva-se garantir os direitos de aprendizagem em Arte a todos os estudantes do estado do Espírito do Santo. Nas canções do memorável capixaba cantor, compositor e poeta Sérgio Sampaio podemos iniciar a nossa conversa sobre o ensino da Arte almejado para as escolas de ensino fundamental do estado, tendo como ponto de partida as produções artísticas e culturais do nosso território. Convidamos os professores de Arte, das diferentes linguagens: Artes Visuais, Dança, Música e Teatro, para apreciarmos a cultura e a Arte de nosso Estado, e pensarmos no ensino da Arte como momentos de apreciação, identificação, experimentação, criação e crítica da cultura local e regional, estabelecendo relações com a produção nacional e internacional. Dessa forma, esse documento intenta que os estudantes dos diferentes municípios do estado do Espírito Santo reconheçam as produções artísticas e culturais que constituem as suas identidades. (CES, 2018).

Utilizando-se das músicas de um artista do próprio estado, o documento intenta chamar a atenção dos professores para a produção local. Além disso, o texto trata de forma evidente o que se pretende com a educação em arte, no ensino fundamental, no Espírito Santo. O texto apresenta várias vezes as palavras identidade, multicultural, diversidade cultural, além de evidenciar, em diversos parágrafos ao longo do texto, essa importância da aproximação com a produção artística local. O texto do currículo também faz menção as diferentes matrizes culturais que compõem a produção artística brasileira e o patrimônio cultural do país.

Apesar de o documento seguir o princípio da educação multicultural em arte alinhando-se com o que está posto pela BNCC e em consonância com o ensino da arte que já estava previsto em documentos anteriores, tais como os PCNs e o currículo anterior do estado, a proposta parece desafiadora para a maioria dos professores. A proposta da educação multicultural em arte necessita ainda de ser difundida e estuda nas redes de ensino.

A educação multicultural vem sendo defendida por diferentes arte/educadores. Ana Mae Barbosa desperta para o cuidado baseada na comunidade já algum tempo:

Arte- Educação baseada na Comunidade é uma tendência contemporânea que tem apresentado resultados muito positivos em projetos de educação para a reconstrução social, quando não isolam a cultura local, mas a discutem em relação com outras culturas. (BARBOSA, 2002, p. 20).

BOTELHO, Claudia. O patrimônio artístico e cultural do estado do Espírito Santo, a reformulação do 86 ensino da arte a partir da Base Nacional Comum Curricular e o uso da tecnologia na prática educativa. Revista GEARTE, Porto Alegre, v. 6, n. 1, p. 80-91, jan./abr. 2019.

Disponível em: http://seer.ufrgs.br/gearte 


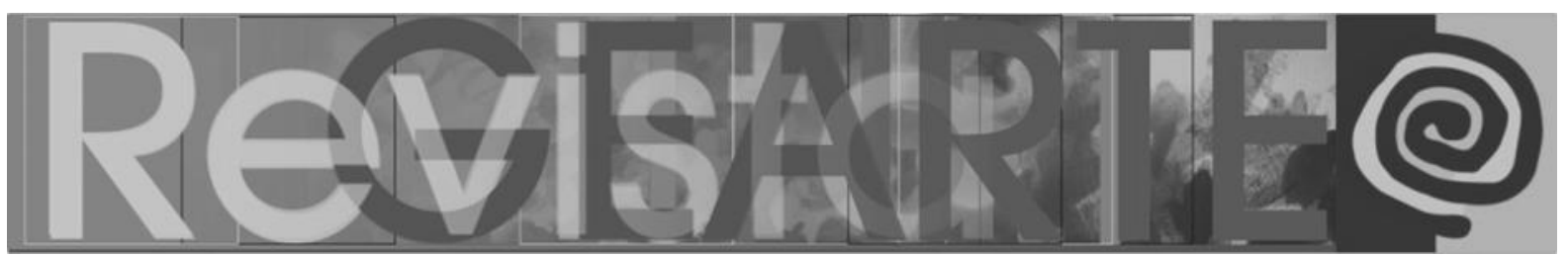

A ideia de uma educação intercultural baseia-se no conhecimento do que se tem no entorno do educando, percebendo as marcas sociais, étnicas, religiosas, econômicas. O reconhecimento dos modos de comportamento, vida, histórias que constituem cada sujeito do processo educativo valoriza culturas que nunca foram priorizadas. Faz com que cada pequena comunidade se identifique como produtores de culturas e histórias.

Ao saber reconhecer e valorizar as culturas não dominantes, os estudantes se encontraram no meio delas e isso lhes abrirá novas perspectivas e visões de mundo. De acordo com Richter, "[...] a educação multicultural e intercultural deve familiarizar os alunos com as realizações de culturas não dominantes, de maneira a colocá-lo em contato com outros mundos, e levando-o a abrir-se para a riqueza cultural da humanidade [...]" (RICHTER, 2002, p. 90).

Vencer a hegemonia cultural dos currículos significa olhar para o entorno dos estudantes compreendendo que suas diferenças os caracterizam e devem ser estudadas valorizando e inter-relacionando com culturas diversas. Assim, Richter consagra que:

[...] o ensino da Arte deve se caracterizar por uma educação predominantemente estética, em que os padrões culturais e estéticos da comunidade e da família sejam respeitados e inseridos na educação, aceitos como códigos básicos a partir dos quais deve-se construir a compreensão e imersão em outros códigos culturais. Trabalhar com a multiculturalidade no ensino da Arte supõe ampliar o conceito de Arte, de um sentido mais restrito e excludente, para um sentido mais amplo, de experiência estética [...] (RICHTER, 2002, p. 91).

As orientações curriculares apenas se farão efetivas nas salas de aulas se os professores assumirem uma postura de curadores e de produtores culturais, sabendo identificar as manifestações de arte e culturais de seu entorno, de diferentes códigos estéticos e saber potencializar as realizações culturais locais que se encontram tímidas ou desvalorizadas:

Considerando que o universo cultural da comunidade em que a escola está inserida precisa ser estudado pelo professor, para que ela possa atuar nesse contexto de maneira eficiente e não invasiva. Especialmente o professor de

BOTELHO, Claudia. O patrimônio artístico e cultural do estado do Espírito Santo, a reformulação do 87 ensino da arte a partir da Base Nacional Comum Curricular e o uso da tecnologia na prática educativa. Revista GEARTE, Porto Alegre, v. 6, n. 1, p. 80-91, jan./abr. 2019.

Disponível em: http://seer.ufrgs.br/gearte 


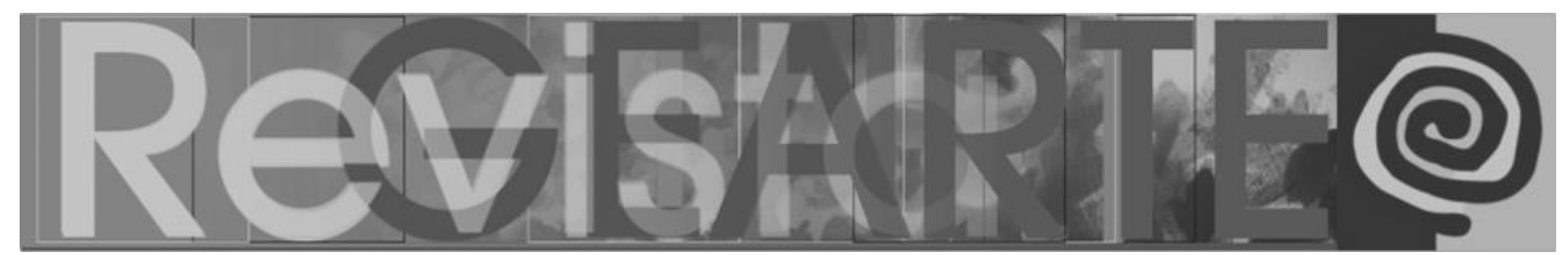

artes precisa conhecer e buscar compreender códigos visuais e estéticos presentes, de maneira a utilizá-los como seu referencial e ponto de partida, construindo a partir daí a abordagem metodológica e a estrutura de códigos a serem trabalhados [...] (RICHTER, 2002, p. 92).

Para se trabalhar a educação multicultural, especialmente no ensino da arte, faz se necessário ainda que os professores conheçam e reconheçam a importância da identificação e valorização do patrimônio artístico cultural de suas localidades, regiões, além do patrimônio artístico cultural nacional e internacional:

A cultura adquire formas diversas através do tempo e do espaço. Essa diversidade se manifesta na originalidade e na pluralidade de identidades que caracterizam os grupos e as sociedades que compõem a humanidade. Fonte de intercâmbios, de inovação e de criatividade, a diversidade cultural é, para o gênero humano, tão necessária como a diversidade biológica para a natureza. Nesse sentido, constitui o patrimônio comum da humanidade e deve ser reconhecida e consolidada em benefício das gerações presentes e futuras. (UNESCO, 2002)

A arte, seja ela erudita ou popular, faz parte da construção da identidade dos indivíduos. Suas características marcam as personalidades, as atitudes, os comportamentos e as histórias das educandos. Reconhecendo suas marcas, ideias e histórias se constrói conhecimentos mais significativos. Assim, torna-se necessário pesquisar, mapear, registrar e reunir informações a respeito do patrimônio artístico e cultural das diversas comunidades. Cada localidade, seja ela urbana: de centro ou periférica; ou rural (de interior ou de litoral), tem suas produções de arte popular ou erudita que se torna objeto de estudos de uma educação multicultural.

No caso do currículo do Espírito Santo para se realizar uma educação multicultural é necessário executar pesquisas sobre a história da arte capixaba e das suas manifestações culturais. Sabemos que muito da produção artística e cultural do estado do Espírito Santo ainda necessita de estudos e pesquisas, principalmente aquelas que se encontram no interior do estado. Assim, torna-se necessário impulsionar e entre os professores a pesquisa do patrimônio cultural do estado do Espírito Santo e tornar esse patrimônio acessível para ser tornar objetos de estudos em salas de aulas. 


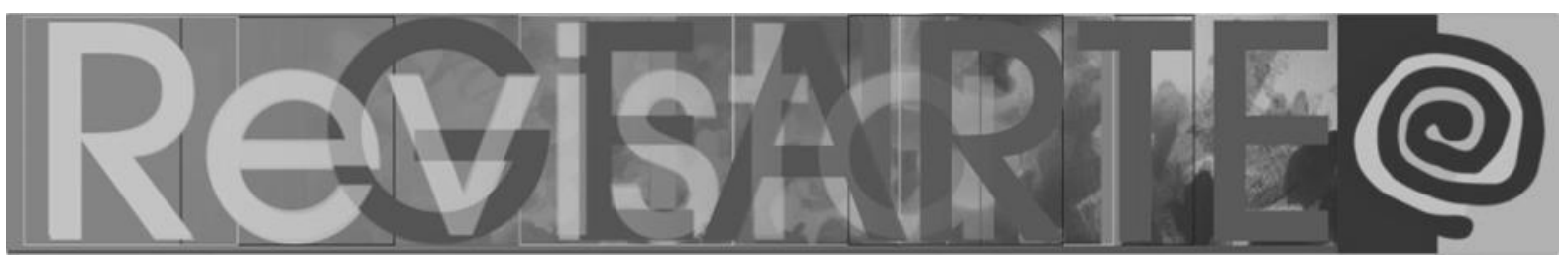

\title{
Tecnologia e práticas de ensino da Arte: O Museu Virtual do Patrimônio Artístico e Cultural do Espírito Santo
}

Diante da proposta de um ensino multicultural de arte viu-se a necessidade de se promover meios para que esse ensino aconteça. A tecnologia é uma via de de realização dessas ações. Na contemporaneidade a tecnologia tornou-se além de uma ferramenta, uma linguagem importante para a educação. Utilizá-la na implementação do novo currículo é uma estratégia de tornar possível uma aproximação do ensino com a diversidade do patrimônio artístico cultural do estado. A dinâmica das tecnologias educacionais pode aproximar as estudantes do interesse pelas diversas culturas.

\begin{abstract}
A busca de novos ambientes de aprendizagem, mais adequados às necessidades e exigências do público discente frente ao mundo universalizado e complexo, enfatiza a importância de iniciativas deste porte. Sendo assim, o site e a sua visão integradora vislumbram o conhecimento em sua totalidade, numa abordagem interdisciplinar necessária e urgente, que evita a fragmentação da atividade pedagógica. (PORTELLA, 2002, p. 134).
\end{abstract}

As ferramentas digitais se mostram um caminho para a integração dos objetos de estudo com as práticas educativas. No componente curricular arte as tecnologias digitais podem aproximar e tornar possível que obra de artes ou manifestações culturais estejam disponíveis e cheguem ao conhecimento de todos com suas devidas informações e características.

Assim como nos demonstra Portella, "A internet é um instrumento poderoso de ação artístico- cultural, por sua inédita capacidade de levar imagens, textos, e documentos hipermídia, possibilitando assim gerar novos paradigmas no âmbito das propostas do ensino da Arte [...]" (PORTELLA, 2002, p. 124).

A internet como um local de alojamento de imagens, sons, informações tornase um aparato para o ensino da arte indispensável, nela podemos reunir informações, divulgar e valorizar obras que antes não eram nem reconhecidas como patrimônio cultural. A ideia de se criar um museu virtual com as produções artísticas e culturais 


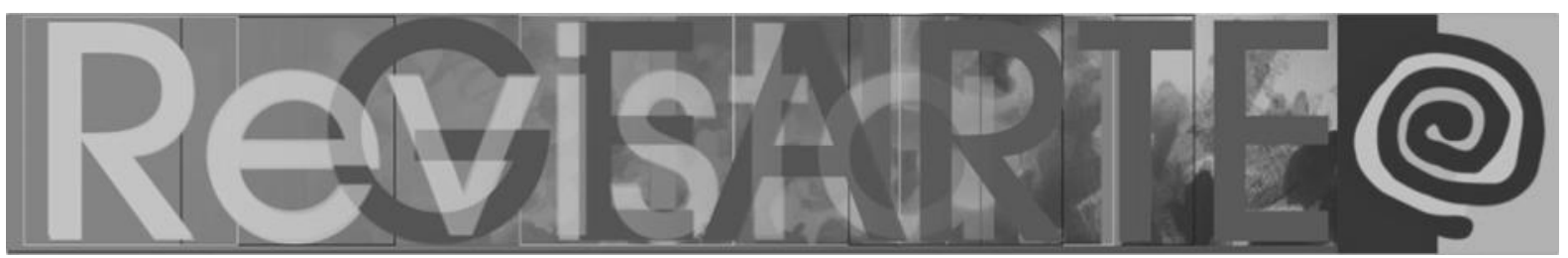

do estado do Espírito Santo tem a possibilidade de cruzar informações de diferentes culturas em âmbito local, regional, nacional e internacional.

A presença de Museus Virtuais na grande rede mundial possibilita o contato com a produção artística em diferentes momentos da história da humanidade. Além do caráter de um mero observador, ao usuário será dada a oportunidade de acesso a registros textuais, linhas de tempo, links para outros sites, participação em listas de discussão, envio de mensagens eletrônicas, consultas a banco de dados, atualidades, eventos relacionados ao museu bem como o de simplesmente navegar. (PORTELLA, 2002, p. 126).

O espaço virtual de um museu do patrimônio artístico cultural pode se desenhar por diferentes formas, fluindo em linhas que podem se direcionar por períodos históricos, tendências estilísticas, características étnicas ou de gênero, entre outros. Além disso, a proposta de um museu virtual pode se estender para um projeto interdisciplinar. Oportunizando a criação de um espaço coletivamente, onde docentes de diferentes locais, junto com seus discentes, podem realizar pesquisas e inseri-las nos sites, criando de forma colaborativa.

As possibilidades criativas e inventivas nos ambientes virtuais geram inúmeras possibilidades que semeiam ideias de integração entre os mais diversos sujeitos culturais, aproveitando essa riqueza em produções inclusivas e sem preconceitos. Em consideração das ideias de Portella vale reforçar que,

Ao estudar os ambientes inteligentes de aprendizagem (AIA) demonstrou que o surgimento e o desenvolvimento das tecnologias educativas pode provocar uma renovação na pesquisa cognitiva, pois as novas tecnologias de tratamento da informação permitem imaginar cenários a fim de assistir e melhorar a eficácia da aprendizagem por meio do ensino (PORTELLA, 2002, p. 127).

Interligar a arte, o ensino e as tecnologias educacionais torna-se uma proposta possível e valorosa para o reconhecimento do legado artístico e cultural de variadas sociedades. Colabora com o reconhecimento das identidades que formam os diversos educandos, trabalhando em sua auto- estima e na sua formação crítica e reflexiva. $\mathrm{O}$ conhecimento de suas características, daquilo que o constitui enquanto sujeito the fazendo não ter vergonha de sua própria história, mas reconhecê-la como produto 


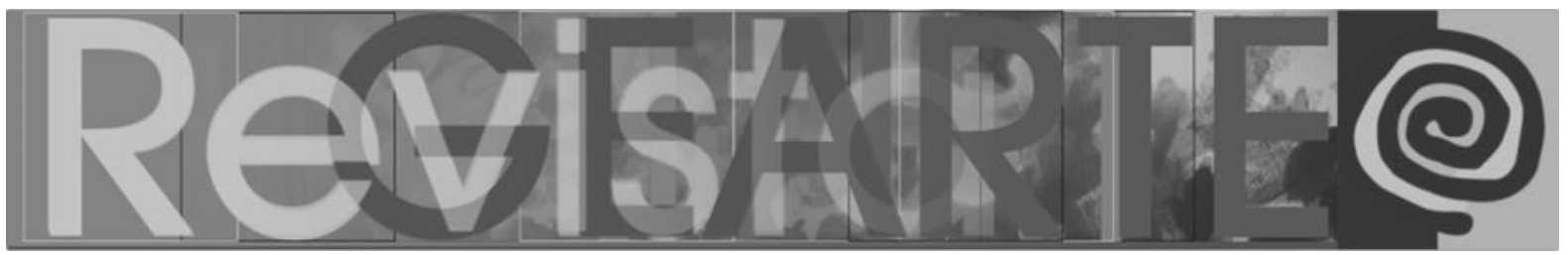

cultural que constrói, junto com outras informações, sujeitos pertencentes e produtores de códigos culturais contido de valores iguais aos das culturas hegemônicas, na maioria das vezes europeias.

\section{Referências}

BARBOSA, Ana Mae (Org.). Arte/ Educação Contemporânea: Consonâncias Internacionais. Editora Cortez: São Paulo, 2006.

BRASIL. Ministério da Educação. Secretaria da Educação Básica. Base Nacional Comum Curricular. Brasília, DF, 2017. Disponível em: <http://basenacionalcomum.mec.gov.br/. Acesso em: 25 de fevereiro de 2019.

BRASIL. Secretaria de Educação Fundamental. Parâmetros curriculares nacionais: arte. Brasília: MEC/SEF, 1998.

GOVERNO DO ESTADO DO ESPÍRITO SANTO. Secretaria de Educação. Currículo do Espírito Santo. Vitória: SEDU, 2018.

MOREIRA; Antº. Flávio; CANDAU, Vera Maria (Orgs.). Multiculturalismo: diferenças culturais e práticas pedagógicas. $2^{\circ}$ ed. Petrópolis, RJ: Vozes, 2008.

PORTELLA, Adriana. Aprendizagem da arte e o museu virtual do projeto Portinari. In.: BARBOSA, Ana Me Barbosa(Org.). Inquietações e mudanças no ensino da arte. Editora Cortez: São Paulo, 2002.

RICHTER, Ivone Mendes. Multiculturalidade e Interdisciplinaridade. In.: BARBOSA, Ana Me Barbosa(Org.). Inquietações e mudanças no ensino da arte. Editora Cortez: São Paulo, 2002.

UNESCO. Declaração Universal sobre a Diversidade Cultural. Paris: UNESCO, 2002.

\section{Claudia Botelho}

Possui graduação em Artes Visuais pela Universidade Federal do Espírito Santo (2008). Especialização em Arteterapia pela Faculdade Saberes e mestrado em Teoria e História da Arte pela Universidade Federal do Espírito Santo (2016). Atualmente atua na Assessoria de Apoio Curricular e Educação Ambiental na Secretaria de Educação do Estado do Espírito Santo. Tem experiência na área de Artes, com ênfase no ensino da Arte e História a Arte Brasileira, atuando principalmente nos seguintes temas: História e Teoria da Arte, Arte- educação, Currículo de Arte, Arte Brasileira, Arte Abstrata, Gravura, Processo de Criação.

E-mail: claudiabotelho.artes@gmail.com

Currículo: http://lattes.cnpq.br/1231491285216913

Recebido em 27 de fevereiro de 2019 Aceito em 21 de abril de 2019 